\title{
15th International Symposium on Information and Communication Technologies in Education (SINTICE)
}

\author{
Javier Torrente, Pablo Moreno Ger, Iván Martínez Ortiz (Guest editors)
}

\begin{abstract}
It is our great pleasure to serve as guest editors for this special issue of the IEEE RITA journal, which holds a fine selection of the most relevant papers presented at SINTICE 2013, the fifteenth international symposium in educational technology held in Madrid in September 2013. The two papers included in this special issue are representative of the high quality observed during all the conference.
\end{abstract}

\section{Index Terms-SINTICE 2013}

\section{INTRODUCTION}

$S_{\mathrm{r}}$ INCE its first edition, the International Symposium on Information and Communication Technologies in Education (SINTICE) has become a reputed international forum for presenting, showcasing and discussing the latest research breakthroughs and innovative practices on learning technologies. SINTICE gathers together all representative actors in the field of educational technologies, including researchers, developers, teachers and institutional representatives to share and discuss their views, knowledge and experience.

It is a pleasure for us to serve as guest editors for this special issue. We also want to transmit our sincerest acknowledgement to the IEEE RITA editorial board for providing us with the opportunity to bring to the readers of the journal this compendium of selected articles from the fifteenth edition of this symposium, held at the School of Computer Science at the Complutense University of Madrid, hosted under the umbrella of the 2013 Spanish Conference on Informatics (CEDI).

The SINTICE 2013 symposium had a clear focus on the application of Web 2.0 technologies to support new pedagogical approaches. Around this broad term 30 papers were selected, after undergoing the uttermost rigorous peer review process. Among them, the best two papers were selected to appear on this special issue, after considerable improvement and extension. The topic of these contributions reflects not only what the SINTICE conference was, but the

Guest editors work at the Department of Software Engineering and Artificial Intelligence of the Complutense University of Madrid, Spain. Email: jtorrente@e-ucm.es, pablom@fdi.ucm.es, imartinez@fdi.ucm.es

DOI (Digital Object Identifier) Pendiente current state of the art in e-Learning from the academic field, addressing highly topical aspects such as Massive Open Online Courses (MOOCs) and the integration of services and eLearning tools for making new educational experiences.

Without further ado, we hope readers will enjoy the papers that are included in this special issue as much as we have enjoyed working on it.

Yours sincerely,

Javier Torrente, Pablo Moreno-Ger and Iván Martínez Ortiz.

\section{SELECTED PAPERS}

These are the two articles selected for this special issue:

- Extending Google Course Builder with Real-World Projects in a Masters' Course, by authors Carlos Delgado Kloos, Pedro J. Muñoz-Merino, and Mario Muñoz Organero.

- Learning Technologies and Semantic Integration of Learning Resources, by authors Juan Manuel Dodero, Manuel Palomo-Duarte, Iván Ruiz-Rube, Ignacio Traverso, José Miguel Mota and Antonio Balderas.

Delgado-Kloos et al address MOOCs from an engineering point of view, describing their work on Course Builder (Google's MOOC platform) in a Master's course, and how it helped them boost their teaching and revolutionized the learning experience for the students.

In the last article, Dodero et al present a technical overview of their work in the ASCETA project, which addresses the integration of heterogeneous online ecosystems such as Virtual Learning Environments (e.g. Moodle), social networks (e.g. Twitter) or reference management systems like Mendeley, in order to generate rich e-Learning environments.

\section{ACKNOWLEDGMENTS}

We want to thank Martin Llamas, and the rest of the editorial board of the IEEE RITA journal, for having the opportunity to disseminate the main results of the 2013 SINTICE symposium through this magnificent forum, as well as the authors who participated in this special issue for the effort invested in improving their articles.

This work has been partially funded by the Spanish Ministry 
for Science and Innovation (project no.TIN2010-21735-C0202); the European Commission, through its Lifelong Learning Programme ("Segan Network of Excellence in Serious Games" - 519332-LLP-1-2011-1-PT-KA3-KA3NW) and the Seventh Framework Programme (RAGE project, Network of Excellence "GALA - Network of Excellence in Serious Games "- FP7-ICT-2009-5-258169), the Complutense University of Madrid (research group GR35 / 10-A-921340) and the Regional Government of Madrid (eMadrid - S2009 / TIC1650).

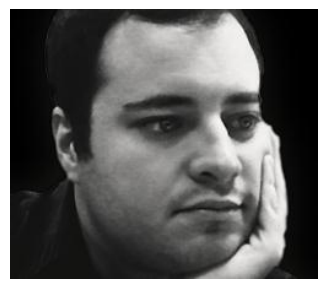

Javier Torrente, $\mathrm{PhD}$, has worked since 2008 as a contract researcher for the e-UCM group. His research focuses on the field of game-based learning in general and the eAdventure (http://e-adventure.e-ucm.es/) project in particular. In recent years, he has developed interest in the field of humancomputer interaction, especially in the development of new interfaces for people with disabilities, the topic of his $\mathrm{PhD}$ dissertation. Results of his research include over 70 publications in international conferences and journals.

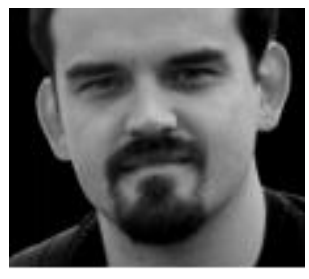

Pablo Moreno Ger, $\mathrm{PhD}$, got his $\mathrm{PhD}$ in Software Engineering from the Complutense University of Madrid (2007). He is currently an Associate Professor in the Department of Software Engineering and Artificial Intelligence of the UCM, where he conducts research and teaching.

His area of research is Technology-Enhanced Learning, and his specific interests focus on the use of games and simulations for educational purposes as well as the integration of these contents with other e-Learning activities. He has written more than 70 articles in conferences and journals related to these lines of work.

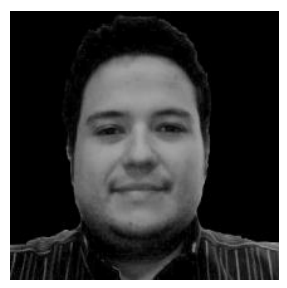

Iván Martínez Ortiz, Ph.D. got his $\mathrm{PhD}$ in Computer Science from the UCM (2011). He is currently an Associate Professor in the Department of Software Engineering and Artificial Intelligence of the UCM, where he has teaching duties and also conducts research. His research interests focus on educational innovation through new technologies, with particular emphasis on educational modeling languages, domain specific languages applied to education and the use of video games and other interactive materials for educational purposes. He has published more than 30 academic articles in this area. Dr. Martínez Ortiz is also a member of the AENOR Technical Committee for Standardization in e-Learning (CTN71/SC36). 